\title{
Economically Destabilizing Electric Power Markets for Profit
}

\author{
V. Petrov, C. W. Richter, G. B. Sheblé \\ Department of Electrical and Computer Engineering \\ Iowa State University \\ Ames, Iowa 50011
}

\begin{abstract}
The deregulation of the electric industry in the United States opens the power market to competition. Buyers and sellers of electric power will be competing for limited resources. Although regulators will attempt to limit such activity, when large amounts of money are at stake, the participants have incentives to engage in destabilizing behavior. The goal of this study is to model agent driven power market auctions where some of the players attempt to benefit from causing economic instabilities and intentionally driving market prices by applying different strategies.
\end{abstract}

\section{Introduction}

Throughout the world, the electric industry is in the midst of major changes designed to promote competition. No longer vertically integrated with guaranteed customers and suppliers, electric generators and distributors will have to compete to sell and buy electricity. The stable electric utilities of the past will find themselves in a highly competitive environment. Some countries and regions of the US (e.g., California, PJM) are already operating in a restructured environment. There does not yet appear to be a standardized final market structure that works for all areas, but each market that springs up adds to our experience and helps us make the next market implementation work a little better and more competitively. The authors believe that, to some degree depending on the market implementation, regional commodity exchanges will play a key role in buying and selling electricity.

With an electricity market that promises to do nearly $\$ 100$ billion of business each year, competition is expected to be stiff. The number of market players will be larger than ever before, and it would be impossible to guarantee that all participants will be trustworthy. It is likely that participants in this market will attempt to gain a competitive advantage if a means to do so arises. Corporate espionage that reveals the strategies of competitors could provide valuable information in developing one's own strategies. Disruptive practices need not be illegal. Loopholes in the regulation may allow a market participant to engage in activities of a questionable nature. It is inevitable that some of the participants in the newly deregulated electric market will try to benefit by employing techniques dealing with the financial aspect of markets like predatory pricing to eliminate competition or purposely inflating the prices. Other malicious actions may deal directly with the physical systems including causing congestion and blackouts/brownouts. In this work attention is paid to the study of the effects of malicious gaming behavior during bidding in agent based power markets.

The remainder of this paper is organized as follows. Section II discusses the methods and techniques employed modeling the agents and markets for the simulations described here. Section III describes the design of the small experiment included in this work. Section IV provides the results and analysis of the simulation. Section V talks about market power. Finally, Section VI presents some conclusions and ideas for future research.

\section{Methods and Techniques}

Different models have been built to simulate the electric marketplace. In this study the scheme outlined in Ref. [1] is used. A bilateral auction is constructed, with a fixed number of buyers and sellers of electricity. The bilateral contracts for fixed amount of electric energy are performed in fixed time intervals. The transmission system is lossless and has unlimited capacity. The trading agents use a fixed set of rules to change the bidding strategy $[2,6]$. The auction bid matching is performed by an independent third side.

One round of bidding proceeds as follows. All buying/selling agents submit their bids/offers to a third party, an Independent Contract Administrator (ICA). ICA matches the bids using an approach similar to Wood and Wollenberg [4,5]. All bids and offers are sorted in descending and ascending order and juxtaposed. If a buy bid is higher than the corresponding sell offer, the two players are matched, a contract is

(C) 1999 by V. Petrov, C. W. Richter and G. B. Sheblé. All rights reserved. 
Table 1. An example of an auction bid matching of 5 sellers/buyers, and the resulting outcomes.

\begin{tabular}{llllll}
\hline Bid & Offer & Quantity & Match & Midpoint & Eq. Price \\
\hline 10.91 & 10.01 & $1 \mathrm{MW} / \mathrm{h}$ & Yes & 10.46 & 10.48 \\
10.76 & 10.07 & $1 \mathrm{MW} / \mathrm{h}$ & Yes & 10.41 & 10.48 \\
10.74 & 10.38 & $1 \mathrm{MW} / \mathrm{h}$ & Yes & 10.56 & 10.48 \\
10.26 & 10.53 & $1 \mathrm{MW} / \mathrm{h}$ & No & N/A & N/A \\
10.05 & 10.67 & $1 \mathrm{MW} / \mathrm{h}$ & No & N/A & N/A \\
\hline
\end{tabular}

approved and the players are notified. In the case where the buy bid is lower than the sell offer, the players are rejected and notified. There is no second call for bidding regardless of the number of contracts approved. A bid and offer midpoint, as well as an equilibrium price is calculated and the next round is called. Table 1 shows an example of 5 buyers and sellers after the bids and offers were matched by ICA. Different pricing techniques can be studied using the model described here. Midpoint prices are calculated, which is used if discriminatory pricing is desired, and if nondiscriminatory pricing is desired, the valid matches weighted by quantity are used to determine equilibrium price. Meanwhile the players update their strategy and the ICA calls for the next round.

Each player updates its strategy according to the outcome of the previous round. The player knows only the outcome of its own last action (e.g. contract accepted/rejected) and remembers the bid/offer value. If the offer was rejected, next time the seller lowers the price, choosing the value randomly within an interval it calculates based on a rule including its own last offer. Accordingly, the buyer bids are higher than the preceding round. If the offer was accepted, the

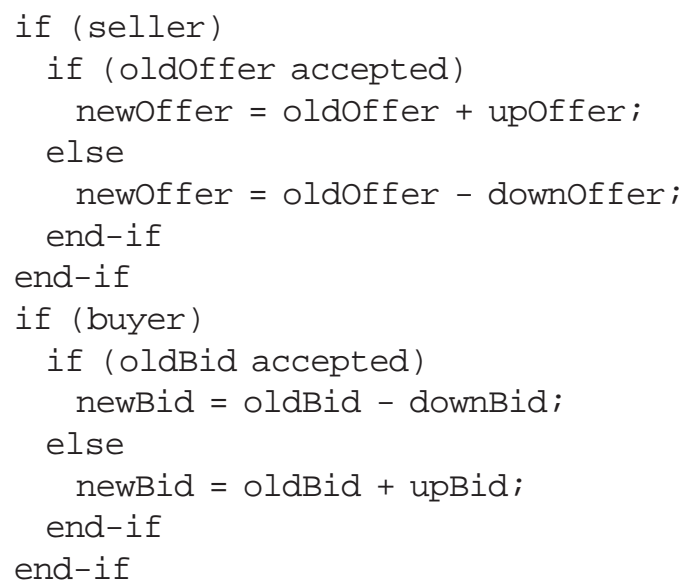

seller offers a higher price based on a rule including the last accepted offer, and the buyer bids are reduced. All players start trading around a fixed equilibrium price submitted by ICA. This is done for convenience. In a real world situation the players can start bidding around the closing price for the previous day, for example. After the first round the ICA takes care only of matching players. Pseudocode is given describing the actions of a seller and buyer depending on the outcome of the last round.

In any event, we must set upBid $<$ downBid, and upoffer < downoffer. If it were otherwise the price would not converge.

\section{Experimental Design}

The described system fairly quickly reaches equilibrium, and the buy/sell spread, the midpoint price and the equilibrium price converge to a limiting value. Fig. 1 shows the pictorial representation of an auction consisting of 100 players, evenly divided into buyers and sellers of electricity. The auction went through 10 rounds. In this case downBid and upOffer were set at $5 \%$ of the last unsuccessful bid/offer and downOffer and upBid were set to $3 \%$ of the last successful bid/offer. All four price updates were tied up to a random generator, i.e. the players may choose price updates with equal probability within the prescribed price update interval.

Such seemingly simple market behavior is very similar to what was observed in experimental double
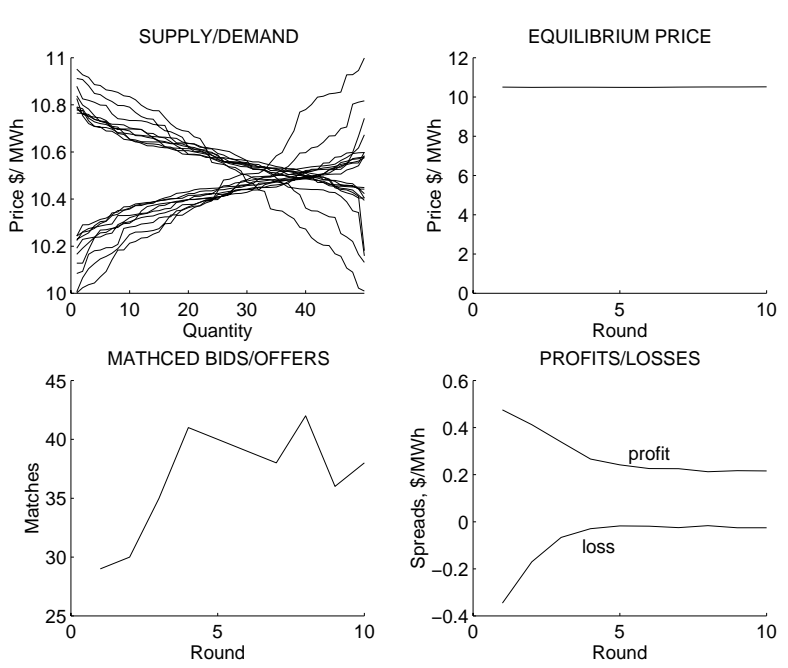

Fig. 1 Supply/demand, equilibrium price, offers accepted and profit/loss spreads for 50 buyers/sellers of electric power after 10 bidding rounds. 
auction markets played by people [4]. It can be seen that the initial price submitted by ICA remained stable, and the number of accepted offers quickly reached about $70 \%$ of the total number of offers submitted, up from about $50 \%$. After only a few rounds the players minimized the losses to almost zero. However, the profits also dropped. The system did not diverge even after simulating a few years of bidding rounds, assuming that each round lasted an hour and players traded fixed amounts of electric power.

\section{Results and Discussion}

After building a stable model of the auction, simulations were run where some of the players misbehaved and attempted different strategies. A few cases were considered. Also, ICA was not allowed to intervene, except to match the submitted bids/offers.

First, one of the sellers attempted consistently to offer lower prices than the others (predatory pricing). The predatory pricing would drive the competition out, justified later by increasing the price by the remaining player, thus creating certain state of monopoly. After calculating the new offer, the resulting price was additionally decreased by $5 \%$. For a 10 buyer/seller auction the effect of one single player occasionally offering lower prices may seem negligible. However, it turned out that the seller was able to drive the price down by more than $10 \%$ only after 100 rounds. The equilibrium price fell off exponentially, approaching zero. Fig. 2 shows the equilibrium price when the

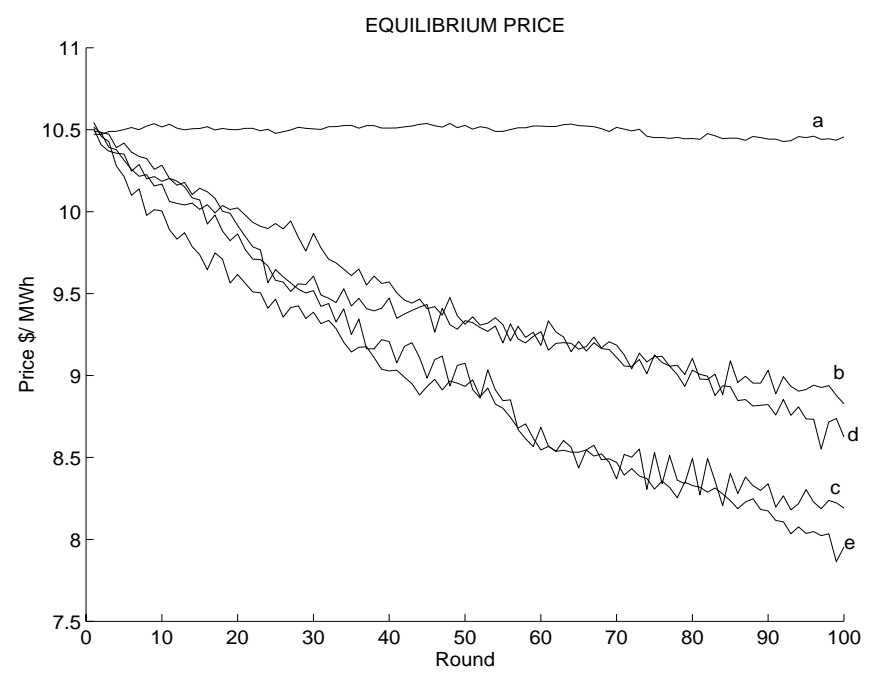

Fig. 2 The effect of predatory pricing on a 10 buyer/ seller auction; a) no price decreasing; b), c), d) and e) predatory pricing by one, two, three and four sellers.

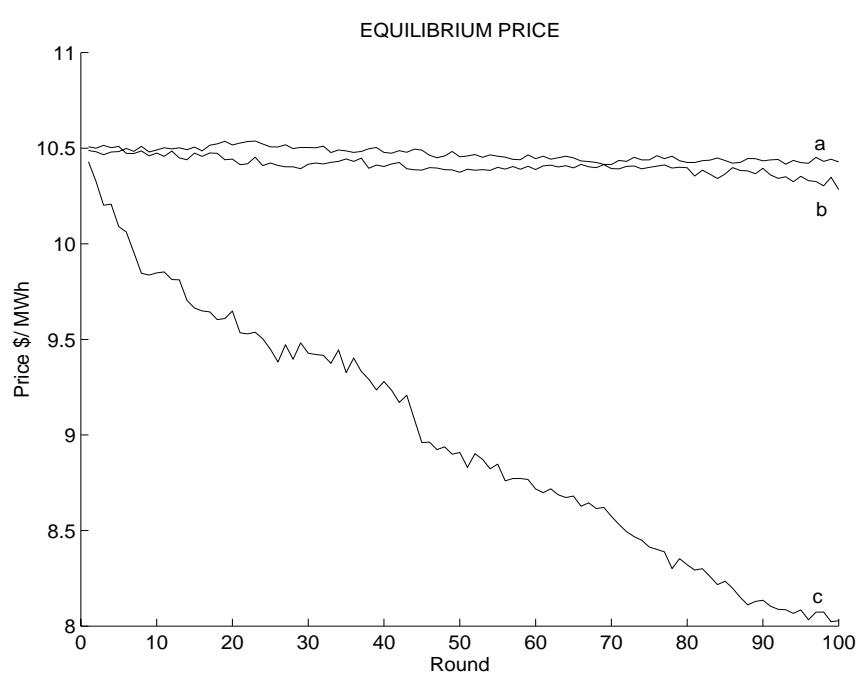

Fig. 3 The effect of predatory pricing; a) equilibrium market; b) Five players against five; c) Nine players against one.

seller's downoffer is on average twice higher than the regular downOffer decrement no matter the outcome of the previous sell offer. The results were averaged over 10 auction runs. The tactic was consequently employed by one, two, three and four sellers. It is interesting to see that after the initial sharp reduction of the equilibrium price by more that $10 \%$, there was no significant difference when the second, third and fourth player engaged in predatory pricing. This suggests that if a company has a few generators, each of them participating in the market, the company may randomly designate each generator as a predator during every round, making it difficult to spot such malicious behavior, yet achieving the goal of lowering the price. This would allow the seller to efficiently eliminate other sellers within some period of time. The effect on the number of successful contracts is as follows: equilibrium market $-62 \%$, one player $-64 \%$ and four players $-69 \%$ of the contracts were approved. The reason for the increase is that as the sellers decrease the price, the supply shifts down, allowing more buyers to make contracts.

Next, a scenario where five and nine of the sellers attempted predatory pricing, thus trying to eliminate the rest of the sellers, was tested. Each time an unsuccessful offer was made, the seller's price was additionally dropped by $5 \%$. Fig. 3 shows the averaged equilibrium price during 100 bidding rounds. The strategy was even more elaborated by allowing each of the predators to offer a consistently lower price only when its last legal bid was rejected. The price is plot- 


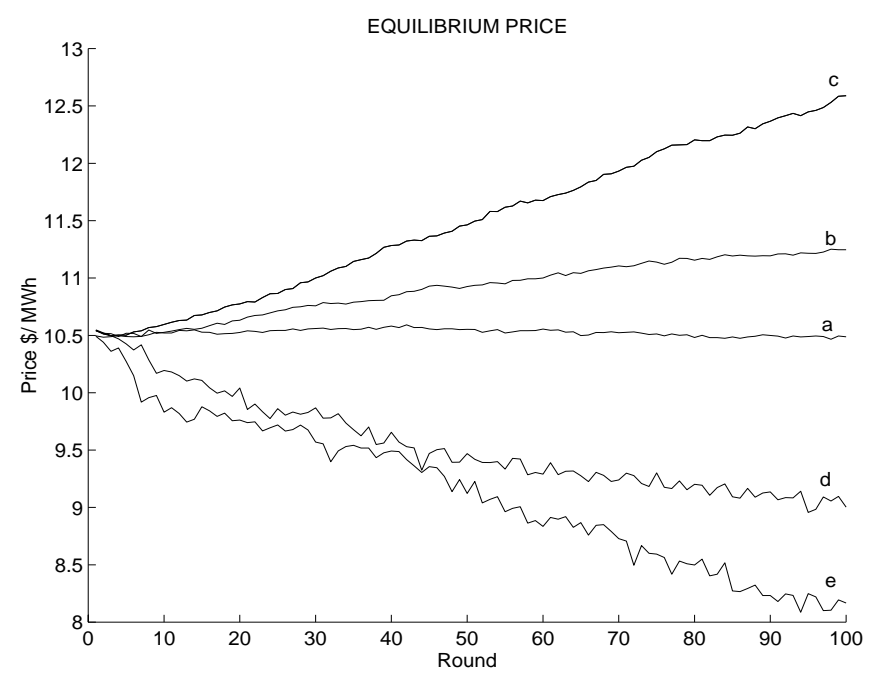

Fig. 4 The effect of price increasing; a) equilibrium market; b) one seller increases; c) two sellers increase; d) one seller decreases; e) two sellers decrease.

ted against an equilibrium market price. It is seen that when 5 players attempt this, there is virtually no effect. It was established that the strategy works only when more than $60 \%$ of the players were engaged. It should be noted that $60 \%$ is the lowest percentage of players successfully making deals on an equilibrium market without predatory pricing. The effect on the number of successful contracts was somewhat similar to that of the previous experiment: equilibrium market $-62 \%$, five players $-62 \%$ and nine players $-68 \%$ of the contracts were approved.

Another case was considered, in which one or more of the sellers are trying to increase the price by consistently offering a $5 \%$ higher price than the rest. Fig. 4. shows the price plotted versus an equilibrium market and versus the case when the same player is trying to lower the price using the same value which was used for overbidding. It is interesting to see that price increasing during the auction is much easier that price dumping. At the beginning of the auction the price is easy to lower, but as time advances, it is easier to increase and more difficult to decrease. The reason is that the auction becomes exponentially stable during price dumping (the price tends to 0 ) and exponentially unstable during price increasing (the price tends to infinity). This is so because the inherent structure of the model does not allow for negative bidding. In that case the number of successful contracts is as follows: equilibrium market $-62 \%$, one player $-60 \%$ and four players $-57 \%$ of the contracts were approved. The reason for the decrease is that as the sellers in- crease the price, the supply shifts up, allowing less buyers to make contracts.

Consideration should be given to assessing the market power of each seller. A seller is said to have unilateral market power if a unilateral deviation from a competitive equilibrium is profitable for that seller, given that all other traders continue to use the strategies that generated the competitive equilibrium [7]. The market power in this case is directly proportional to the market share. In a 10 seller market each seller has $10 \%$ of the market share, hence $10 \%$ market power, given that all sellers trade fixed amounts of electricity and all buyers are willing to buy regardless of the price. The situation would get complicated if unequal quantities of electricity are traded, if the buyers also have market power, if the number of buyers does not equal the number of sellers and each traded unit of electricity has different characteristics (reliability for example).

\section{Conclusion and Future Work}

A double auction market of electricity was modeled, and different scenarios for malicious activities from the sellers' side were considered and simulated. It was shown that under proper circumstances some of the players can significantly influence the market thus benefiting themselves. Further work has to be done to asses the effect of buyers on such an auction market. Another direction into which the research might go is estimating the market power of agents under different market conditions. Also, probabilistic analysis of the auction model similar to Ref. [4] should be carried out, which will allow for a priori estimation of the effect of different actions of buyers and sellers on the market. It is important to note that this is a work in progress and future improvements of the model, like implementing a power grid, modeling congestion and including smart agents, is considered.

\section{References}

1. M. T. Bisat, C. W. Richter, G. B. Sheblé, Using Adaptive Agents to Study Bilateral Contracts and Trade Networks, Iowa State University, IA 50011 (1996).

2. A. Wood, B. Wollenberg, Power Generation, Operation and Control, New York, NY: John Wiley \& Sons, 1984.

3. C. W. Richter, D. Ashlock, G. Sheblé, Effects of 
Tree Size and State Number on GP-Automata Bidding Strategies, Iowa State University, IA 50011 (1995).

4. D. Cliff and J. Bruten, Zero is Not Enough: On the Lower Limit of Agent Intelligence for Continuous Double Auction Market, Hewlett-Packard Laboratories, Bristol, UK, (1996).

5. Gerald B. Sheblé, Computational Auction Mechanisms for Restructured Power Industry Operation, Kluwer Academic Publishers, ISBN 0-7923-8475X, (1999).

6. Gode, D. K. and Sunder, S. Allocative Efficiency of Markets with Zero-Intelligence Traders: Market as a Partial Substitute for Individual Rationality, Journal of Political Economy, 101 (1), 119137, (1993).

7. J. A. Kagel and A. E. Roth, A Handbook of Experimental Economics, Princeton University Press, Princeton, NJ (1995).

\section{Biographies}

Valentin Petrov received an MS degree in Physics from Sofia University, Bulgaria in 1993, specializing in plasma physics. After three years working for Varian
Assoc. he continued studying Physics at Bowling Green State University earning an MS in nonlinear optics in 1998. Presently he is pursuing a graduate degree in Electrical Engineering at Iowa State University.

Charles W. Richter, Jr. received his BSEE from South Dakota State University in 1992. After working at a nuclear power plant and a consulting firm, he studied power systems at Iowa State University where he earned an MS (1996) and PhD (1998) in power systems. Presently he is a temporary assistant professor at ISU. Professional interests include economics of power system operations, market modeling and complex adaptive systems.

Gerald B. Sheblé (M 71, SM 85, F 98) is a Professor of Electrical Engineering at Iowa State University, Ames, Iowa. Dr. Sheblé received his BS and MS degrees in Electrical Engineering from Purdue University, and his Ph.D. in Electrical Engineering from Virginia Polytechnic. His more than fifteen years of industrial experience include projects with public utilities, research and development, computer vendors and consulting firms. His research interests include power system optimization, scheduling and control. 